\title{
Quando a direita bateu continência e a esquerda radicalizou, foi para a rua e acabou na prisão: tudo sob os holofotes da imprensa escrita**
}

\author{
Christa Berger*
}

\begin{abstract}
Résumé: Ce texte situe le Brésil dans le contexte des mouvements qui, internationalement, ont marqué 1968 et met en évidence la tension résultant de l'endurcissement du régime militaire et des tentatives de résistance à celui-ci. Il étudie spécifiquement la situation de la presse brésilienne, laquelle a subi de nombreuses contraintes (lois, censure, emprisonnement de journalistes) qui s'opposent à sa fonction d'informer et altèrent la production de l'information, en lui donnant une nouvelle forme. Ces contraintes font aussi naître et s'épanouir un nouvel espace informatif: la presse alternative, dont il est présenté un bref panorama ainsi qu'une réflexion sur la disparition de celle-ci.
\end{abstract}

Palavras-chave: imprensa brasileira, jornais alternativos, censura, lei de imprensa.

Na década de sessenta, como ensina Hobsbawm ( 1995), o centro de gravidade do consenso que faz fluir a história girou para a esquerda. A Era de Ouro - em que "você nunca esteve tão bem" na Inglaterra, e dos "trinta anos gloriosos" da França - que deu aos países capitalistas desenvolvidos a condição econômica de bem-estar social, dava sinais de desgaste. Com o reservatório de mão-de-obra do boom industrial começando a esgotar, os trabalhadores retornavam à luta de classes, reivindicando, nas condições de mercado, empregos e salários. Quando a universidade passou a limitar o ingresso de alunos, formando profissionais adequados ao sistema e alheios aos problemas sociais, os estudantes se mobilizaram para afirmar que a aquisição do saber profissional deve vir acompanhada de reflexão crítica sobre a utilidade social deste saber, e que a universidade não tinha por função produzir quadros dóceis, mas homens e mulheres aptos a se defrontar com duas dimensões da liberdade: a inserção na sociedade e a impugnação simultânea desta mesma sociedade. O movimento estudantil transformou-se em um happening de solidariedade, de explosão criativa, de radicalidade, oferecendo ao mundo uma grande manifestação política e um embate jornalístico.

Nos países subdesenvolvidos, os ecos da fartura evidenciavam as desigualdades e traziam desassossego, mas os gestos de rebeldia, também inspiravam a condução dos acontecimentos. A década se encaminhava para um ano síntese: liberdade e repressão andavam de mãos dadas. A miséria da nascente sociedade de consumo atraía e repelia, na ambigüidade que lhe é inerente.

1968 é maio em Paris. A explosão libertária, a imaginação, o humor, o excesso. É o pátio da Sorbonne, os debates no Odéon, as manifestações gigantescas, as passeatas que desembocam nas portas das fábricas, selando a aliança dos estudantes com os operários. É o incêndio da Bolsa de Paris aos gritos de "arde, templo dos bezerros", são as barricadas e as perseguições noturnas, em que as mulheres são chamadas de putas, as granadas entram pelas janelas abertas, e os estudantes se escondem nos vãos das escadas.

$\mathrm{Na}$ época, o escritor mexicano Carlos Fuentes, disse: "Nosotros, los latinoamericanos, ligados a Francia por tantos motivos del corazón y de la cabeza, debemos felicitarnos de que hayan sido los estudiantes, intelectuales e obreros franceses, los primeros actores de esta gran transformación. A través de Francia, podemos comprender y ser comprendidos. Esta revolución también es la nuestra. Es solo el comienzo. La lucha continúa."( FUENTES, 1968, p.23).

\footnotetext{
** Versão revisada e corrigida do texto originalmente publicado em: PONGE, Robert (Org.). 1968, o ano das muitas primaveras. Porto Alegre: Unidade Editorial da Secretaria Municipal de Cultura da Prefeitura Municipal, 1998. p. 93-101.

* Christa Berger é jornalista, doutora em Ciências da Comunicação pela ECA/USP, professora aposentada da Faculdade de Comunicação da UFRGS, professora titular do Programa de Pós-graduação em Comunicação da Unisinos. Pesquisadora CNPq.
} 
1968 é a noite de Tlatelolco no México. Os estudantes que continuariam a luta de seus colegas franceses, no país de Carlos Fuentes, foram enterrados com seus sonhos.( PONIATOWSKA, 1971). Na América Latina é assim: a morte nos espreita por todos os lados - fome, guerrilha, ditadura. Nas ruas, nas prisões, nas escolas, nas fábricas. A morte é a senha que anuncia nossa história.

No Brasil, o 68 simbólico começa em março, com a morte, no dia 28, do estudante Édson Luis Lima Souto, no Calabouço. O enterro, as missas da Candelária, a passeata e a preparação da passeata dos cem mil, três meses depois, mais os conflitos da Maria Antônia. Os Festivais de música encontram seu desfecho em dezembro com o Ato Institucional $\mathrm{n}^{\circ} 5$.

No ano que sintetiza a década não há fala mansa ou conciliação. As matrizes dos posicionamentos são claras e antagônicas. Ou se é de direita ou se é de esquerda. Jean-Paul Sartre e Raymond Aron, por exemplo, precisam espaço para afirmar suas idéias, polemizar e tornar públicas suas divergências. A imprensa, assentada sobre o conceito positivista de neutralidade e imparcialidade, é convocada a descer do muro. A Sociedade dos Jornalistas Franceses proclama: "a imprensa só é livre quando não depende nem do poder governamental nem do poder do dinheiro, senão exclusivamente da consciência dos jornalistas e de seus leitores." "Jornalistas e tipógrafos vigiavam as redações impedindo a publicação de notícias contrarevolucionárias.

$\mathrm{Na}$ Alemanha, o movimento estudantil teve, entre suas bandeiras, a luta contra a miséria comunicacional do império Alex Springer. O Bild Zeitung distorcia de forma ostensiva os acontecimentos, confundindo os estudantes do movimento com criminosos, identificando cabelos compridos com marginalidade. Quando professores e intelectuais se preparavam para um grande debate na Universidade de Berlim sobre Springer e seus periódicos, o reitor cancelou, sem justificativa, o encontro. E quando os estudantes tentaram bloquear a saída dos jornais do grupo, a polícia garantiu a expedição.

Ao lado da grande imprensa que seguiu seu rumo atravessando $68 \mathrm{sem}$ constrangimentos, um novo tipo de jornalismo foi surgindo. Libération, Lotta Continua e Blatt tinham a pretensão de serem porta-vozes do movimento em seus países - França, Itália, Alemanha, respectivamente. O primeiro, fundado por Sartre, produzido inicialmente como um panfleto, fez durante muitos anos um jornalismo militante. Assim como Le Monde chegara à geração do pós-guerra, o Libe representava os intelectuais comprometidos.

Lotta Continua, jornal do partido do mesmo nome, que rompeu com a esquerda ortodoxa italiana juntamente com as rádios livres, buscava, com uma linguagem delirante, humanizar as notícias. Os jornais desta tendência criticavam a concepção da notícia como mercadoria, estimulando a reportagem na primeira pessoa, autorizando enfoques subjetivos em trabalho coletivo e com administração cooperativa.

A repercussão que o movimento obteve na grande imprensa, o espaço que conquistou para a polêmica, a transparência que deu da ideologia dos jornais, bem como a geração de novos modelos para fazer jornalismo, permitem reconhecer a importância de 68 também para o destino da indústria cultural. Até então, a esquerda acusava a imprensa de manipuladora e, não poucos, propunham, como alternativa, folhas mimeografadas distribuídas de mão em mão. 68 contribuiu para que alguns assimilassem as novas possibilidades tecnológicas também para a revolução e para que os intelectuais olhassem a imprensa como lugar de exposição de suas idéias. Mas, principalmente, serviu como estímulo para o investimento político e cultural em periódicos.

No Brasil, o golpe militar atingiu, de frente, a imprensa. De 64 a 68, muitos jornais populares, independentes ou de partido, deixaram de existir. Novos Rumos (PCB), O Panfleto (Leonel Brizola), A Classe Operária (PC do B), Brasil Urgente (padres dominicanos); a censura retrai a grande imprensa - já no dia $1^{\circ}$ de abril, fuzileiros navais ocuparam as redações do Jornal do Brasil, Tribuna de Imprensa, O Globo e Última Hora - e a televisão é introduzida como meio massivo, inaugurando um discurso vazio de conteúdo político e de entretenimento fácil.

Os militares foram pródigos em elaborar leis para coibir a circulação de idéias. Uma nova Lei de Imprensa foi instituída em 1967, que dizia "mesmo que o jornalista tenha provas irrefutáveis de qualquer crime cometido por figuras do governo não poderá divulgar nada sobre o assunto, pois não se admite a prova da verdade quando esta trata do Presidente da República e de Ministros de Estado". Por esta lei, o ministro da Justiça podia determinar a apreensão, independente de mandado judicial, de qualquer jornal ou revista que "contenha propaganda de guerra, promova o incitamento à subversão da ordem política e social e ofenda a moral pública e os bons costumes."

\footnotetext{
${ }^{1}$ Ver: Cuadernos de Marcha, n.15, julio de 1968, p.13.
} 
O poder intimidatório foi reforçado com outra lei, a de Segurança Nacional, em 1969. Em seu artigo 16, a LSN previa a detenção de até um ano para o "jornalista que divulgar, por qualquer meio de comunicação social, notícia falsa, tendenciosa, ou fato verdadeiro truncado ou deturpado, de modo a indispor o povo com as autoridades constituídas". Se essa divulgação "provocar perturbação da ordem pública ou expuser o bom nome, a autoridade, o crédito ou o prestígio do Brasil", a pena aumentaria para cinco anos. Ofender moralmente "quem exerça a autoridade, por motivos de facciosismo ou inconformismo político-social" sujeitou, de 1969 a 1978, os jornalistas brasileiros a penas que variavam de três a seis anos de prisão.

Graças ao decreto-lei no 898, o Ministro da Justiça teve seu poder confirmado e ampliado, podendo não só determinar a apreensão dos impressos, como suspender sua impressão, circulação, distribuição ou venda em todo país. No caso de reincidência, o ministro tinha também a possibilidade de cancelamento do registro do órgão.

Além deste arsenal legal, a imprensa brasileira, com o AI-5, passou a sofrer censura prévia. 1968 é, portanto, para a memória brasileira, também o ano em que a imprensa e os jornalistas foram derrotados.

A Tribuna da Imprensa, de Hélio Fernandes, teve a redação invadida por censores militares em outubro de 68, dois meses antes do Ai-5. O Jornal do Brasil foi colocado sob censura prévia e, no dia 14 de dezembro, um dos diretores e o editor-chefe foram presos. O Estado de São Paulo, o Jornal da Tarde e uma dezena de jornais regionais tiveram edições apreendidas pela polícia. A razão era a mesma: os militares não queriam que a imprensa falasse de sua derrota na tentativa de processar o deputado federal Márcio Moreira Alves, pretensão negada pelo Congresso, que acabou sendo fechado por tropas militares. A proprietária do jornal carioca Correio da Manhã, o periódico de mais declarada oposição no pós-golpe, Niomar Muniz Sodré Bittencourt, presa pelo DOPS, ficou setenta dias encarcerada junto a presas comuns, vinte e três dos quais incomunicável. A alegação das autoridades foi a publicação de artigos e reportagens tendenciosos. Em editorial intitulado "Retirada" e publicado na primeira página da edição do dia 11 de setembro de 1969, a proprietária anunciava sua capitulação, denunciando todas as pressões que motivaram o arrendamento do jornal a terceiros.

Jornalistas foram presos e perseguidos judicialmente. O correspondente do Le Monde foi expulso do Brasil. Antonio Callado e Léo Guanabara, além de perderem seus direitos políticos por dez anos, foram proibidos de "exercer atividades de jornalismo em empresas jornalísticas ou estações radiodifusoras de som e imagem, assim como as de magistério em qualquer nível". Nem mesmo o colunista social Ibrahim Sued passou ileso por este período. No ano em que o Ministro da Justiça afirmava categoricamente não haver censura à imprensa, ele não resistiu e denunciou: "Estou deprimido e revoltado, pois não foi para isso que agi em 64 enfrentando o Brizola, quando muita gente estava em cima do muro... Fui anunciar que o general Meira Mattos visitou o presidente Costa e Silva em companhia do general Portela e tiraram a emissora do ar. A notícia foi baseada no noticiário da Agência Nacional. Minha coluna no $O$ Globo está com censura permanente. Como não posso dizer mais nada a respeito, nem a respeito do meu amigo marechal Costa e Silva, passei a desconhecer a sucessão. Espero que esta situação seja transitória, porque se não terei de abandonar o jornalismo e a televisão.( MARCONI,1980).

A censura que regeu a imprensa por nove anos foi de dois tipos: a primeira, através de bilhetinhos e telefonemas que determinavam os assuntos que não deveriam ser abordados; a segunda, chamada censura prévia, com censores revisando todo o material antes de ser editado. No começo, as redações eram visitadas todos os dias por agentes da polícia federal com papéis timbrados e assinados por alguma autoridade, contendo os assuntos que não deveriam ser abordados. Num segundo momento, já mais informal, os temas eram censurados através de telefonemas. Este relaxamento se deveu à rápida assimilação por parte dos grandes jornais da nova rotina de trabalho; por concordância política ou para garantir a sobrevivência econômica do jornal, a maioria dos proprietários não resistiu, sequer quando eram convidados a veicular notícias plantadas pela polícia sobre fugas ou atropelamentos de presos políticos. Aos que se rebelaram contra os bilhetinhos e telefonemas, restou a presença dos censores a lerem, nas redações ou oficinas gráficas, todos os originais produzidos pelos jornalistas. A Tribuna de Imprensa esteve por quase dez anos sob censura prévia. E os semanários alternativos - Pasquim, Opinião, Movimento, Politika, O São Paulo - já nasceram sob esta condição.

Algumas manifestações de resistência da grande imprensa, marcaram este período. O Estado de São Paulo e o Jornal da Tarde, ambos pertencentes à família Mesquita, em agosto de 1972 tiveram seu prédio cercado pela polícia sob a alegação de que pretendiam publicar "matéria capaz de abalar o regime" e suas edições foram submetidas aos censores até 1975. Os espaços das matérias censuradas eram preenchidos com poesia e 
receitas culinárias, fazendo com que os jornais fossem disputados nas bancas e transformados em opositores do regime. As palavras ausentes tanto quanto os espaços vazios informavam, nestes tempos, mais do que os comunicados oficiais.

A experiência mais marcante do jornalismo brasileiro deste período é, no entanto, a da imprensa alternativa. Com os periódicos de oposição fechados - inclusive o nacionalista Reunião, editado por Ênio Silveira, e o humorístico Pif-Paf, de Millôr Fernandes, que saiu de circulação quando propôs o presidente Castelo Branco para miss Brasil - e a grande imprensa, ao mesmo tempo, amordaçada e conivente com a censura, surgem tímidos, mas vigorosos, os jornais que irão conquistar os leitores, provocar o governo militar e garantir, nas entrelinhas, com humor e inteligência, que o cenário brasileiro não ficasse sem registro. Pasquim foi lançado em 1969 ridicularizando os símbolos e slogans criados pela ditadura, como "Brasil, ameo ou deixe-o" e "Ninguém segura este país". Em 1970, quase todos os seus jornalistas são detidos durante dois meses na Vila Militar. Somem os contratos publicitários. O II Exército adverte a Volkswagen: "Anúncio no Pasquim nos consideramos a subvenção da subversão". Quando a censura prévia foi retirada do jornal cinco anos depois - o Pasquim passou a ser vítima de apreensões, inquéritos e processos.

Em 1972, é lançado Opinião, o mais político dos jornais alternativos deste período. Financiado pelo empresário Fernando Gasparian e produzido por um grupo de jornalistas que tinha a experiência do jornal Amanhã e das revistas Veja e Realidade, o semanário chegou a vender quarenta mil exemplares. A censura veio no número oito e atuou de maneira relativamente branda até o número vinte e três, quando, burlando os censores, o jornal noticiou a morte do estudante Alexandre Vanucchi Leme e a missa de sétimo dia realizada na Catedral da Sé, em São Paulo, com a presença de cinco mil pessoas. A partir daí a censura foi mais rigorosa e o jornal, editado no Rio de Janeiro, ficou obrigado a remeter, semanalmente, todas as matérias da edição para Brasília e, nesta situação, ficou de 1973 a 1977, quando, não suportando mais estes obstáculos e divergências internas, fechou depois de duzentas e trinta e uma edições.

$\mathrm{Na}$ origem dos projetos alternativos da época havia, invariavelmente, uma situação de fechamento de espaços na grande imprensa, o que empurrava um grupo de jornalistas em direção a uma nova experiência. Junto a este estímulo jornalístico somava-se o clima revolucionário das gerações dos anos sessenta e setenta. Assim, os primeiros jornais alternativos foram instrumentos de resistência, unificando jornalistas, intelectuais e militantes na perspectiva de contribuir com a revolução em marcha. Numa segunda fase, os alternativos, acompanhando a abertura política, trouxeram os partidos clandestinos e as utopias emancipadoras ao espaço público emergente. Estudiosos da imprensa alternativa contabilizam cerca de cento e cinqüenta títulos surgidos neste período, com destaque para, além dos três mais significativos - Pasquim, Opinião e Movimento - , Em Tempo, Coojornal, Versus, Bondinho, Informação, Amanhã, De fato, Política, Ex, Brasil Mulher e Nós, Mulheres. Também as organizações políticas assumiram seus jornais: Hora do Povo (MR8), Tribuna da Luta Operária (PC do B), Voz da Unidade (PC) e, já na década de oitenta, em nova conjuntura, o Jornal dos Trabalhadores, do PT.

Por isso, é possível afirmar que a história das esquerdas no Brasil de 1968 a 1977, se confunde com a história da imprensa alternativa. Tanto que o conflito no jornal Movimento, em abril de 77, que dá origem ao Em Tempo, expressa a reorganização da esquerda brasileira.

Sem censura, estes jornais contribuem com a luta pela democratização do país. A grande imprensa, diária, muitas vezes corre atrás das denúncias semanais destes jornais. E, como há leitores e não há impedimentos legais, a grande imprensa busca assemelhar-se aos jornais alternativos, chamando de volta os jornalistas pródigos e abrindo espaço para os seus temas. A nova fase da vida política nacional redefine, também, o lugar de atuação dos jornalistas e a constelação dos jornais. "Opor-se ao governo" - diz Bernardo Kucinski "deixou de ser monopólio da imprensa alternativa. Além disso, a retomada da atividade política clássica, no âmbito dos partidos e de seus jornais, que após a decretação da anistia saíram da clandestinidade, esvaziou a imprensa alternativa de sua função de espaço de realização sócio-política.( (KUCINSKI, 1991)

A imprensa alternativa foi deslizando para o desaparecimento no contexto do fim da ditadura, da abertura política, da reestruturação da grande imprensa, do envelhecimento de sua linguagem e da ausência de cultura política que marca o presente. Não é consensual a discussão sobre o fim da imprensa alternativa, mas não é aqui o lugar para desenvolver esta polêmica."

\footnotetext{
${ }^{2}$ A hipótese corrente é de que os jornais alternativos faziam parte da lógica da ditadura; com o fim desta, os jornais perdem sua razão de ser. Esta discussão encontra-se refletida no livro de Bernardo Kucinski, que problematiza a questão com Raimundo Pereira, um dos principais jornalistas articuladores desta época.
} 
Nos anos noventa, o centro de gravidade que faz andar a História, gira para a direita, outra vez. Jornais militantes perdem sentido, as denúncias vendem jornal e se transferem para a grande imprensa que opta pela função mercantil, espetacularizando-as. Direita e esquerda já não definem a fidelidade a um jornal. Projetos gráficos orientam opções de leitura. Depois de crises de identidade, os alternativos do movimento de 68 lutam pela consolidação econômica. Mais profissionais e menos radicais, alguns, como Libération, sobrevivem. Os jornais conservadores da época seguem sua trajetória de concentração e, fortalecidos, formam grandes monopólios. Morrem os jornais de pequenas tiragens. Springer avança com seu conglomerado após minar a sustentação financeira das revistas Stern e Spiegel, acusando-as de "ameaçar a ordem social alemã".

Enquanto elas têm prejuízos enormes, o seu império floresce. Este modelo vinga no mundo, inclusive no Brasil e em Porto Alegre.

Ao olhar 1968, trinta anos depois, entre manchetes de jornais, livros de História, filmes e relatos, o ano se ilumina por entre passeatas, rebeliões, mortes, censura e resistência. O ano de 1968 das nossas vidas, só é o emblemático 68, com o passar do tempo. Maio francês, Primavera de Praga, os hippies norte-americanos, que se negam a morrer no Vietnã, são matérias da página de política internacional do Correio do Povo e formam o pano de fundo do nosso enfrentamento com o professor que não nos deixa discutir em sala de aula, ou das conversas sussurradas que nos pedem opção pela VPR ou a AP. Inevitável, o nosso 68 espia pelo 68 histórico que estamos a recordar.

Bibliografia

HOBSBAWM, Eric. Era dos extremos: o breve século XX (1914-1991). Trad. do inglês por Marcos Santarrita. São Paulo: Companhia das Letras, 1995.

Cuadernos de Marcha, n.15. Julio de 1968.

PONIATOWSKA, Helena. La Noche de Tlatelolco. México: Era, 1971.

MARCONI, Paolo. A censura política na Imprensa Brasileira. São Paulo: Global, 1980.

KUCINSKI, Bernardo. Jornalistas e Revolucionários nos tempo da Imprensa Alternativa. São Paulo: Scritta Editora, 1991. 